\title{
Homozygous variant p. Arg90His in NCF1 is associated with early-onset Interferonopathy: a case report
}

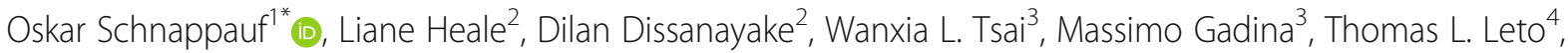
Daniel L. Kastner ${ }^{1}$, Harry L. Malech, Douglas B. Kuhns ${ }^{5}$, Ivona Aksentijevich and Ronald M. Laxer ${ }^{2}$

\begin{abstract}
Background: Biallelic loss-of-function variants in NCF1 lead to reactive oxygen species deficiency and chronic granulomatous disease (CGD). Heterozygosity for the p.Arg90His variant in NCF1 has been associated with susceptibility to systemic lupus erythematosus, rheumatoid arthritis, and Sjögren's syndrome in adult patients. This study demonstrates the association of the homozygous p.Arg90His variant with interferonopathy with features of autoinflammation and autoimmunity in a pediatric patient.

Case presentation: A 5-year old female of Indian ancestry with early-onset recurrent fever and headache, and persistently elevated antinuclear, anti-Ro, and anti-La antibodies was found to carry the homozygous p.Arg90His variant in NCF1 through exome sequencing. Her unaffected parents and three other siblings were carriers for the mutant allele. Because the presence of two NCF1 pseudogenes, this variant was confirmed by independent genotyping methods. Her intracellular neutrophil oxidative burst and NCF1 expression levels were normal, and no clinical features of CGD were apparent. Gene expression analysis in peripheral blood detected an interferon gene expression signature, which was further supported by cytokine analyses of supernatants of cultured patient's cells. These findings suggested that her inflammatory disease is at least in part mediated by type I interferons. While her fever episodes responded well to systemic steroids, treatment with the JAK inhibitor tofacitinib resulted in decreased serum ferritin levels and reduced frequency of fevers.

Conclusion: Homozygosity for p.Arg90His in NCF1 should be considered contributory in young patients with an atypical systemic inflammatory antecedent phenotype that may evolve into autoimmunity later in life. The complex genomic organization of NCF1 poses a difficulty for high-throughput genotyping techniques and variants in this gene should be carefully evaluated when using the next generation and Sanger sequencing technologies. The p.Arg90His variant is found at a variable allele frequency in different populations, and is higher in people of South East Asian ancestry. In complex genetic diseases such as SLE, other rare and common susceptibility alleles might be necessary for the full disease expressivity.
\end{abstract}

Keywords: Autoinflammation, Autoimmunity, Interferons, Systemic lupus erythematosus, NCF1

\footnotetext{
* Correspondence: oskar.schnappauf@nih.gov

'National Human Genome Research Institute, National Institutes of Health, Bethesda, USA

Full list of author information is available at the end of the article
}

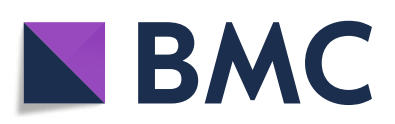

(- The Author(s). 2021 Open Access This article is licensed under a Creative Commons Attribution 4.0 International License, which permits use, sharing, adaptation, distribution and reproduction in any medium or format, as long as you give appropriate credit to the original author(s) and the source, provide a link to the Creative Commons licence, and indicate if changes were made. The images or other third party material in this article are included in the article's Creative Commons licence, unless indicated otherwise in a credit line to the material. If material is not included in the article's Creative Commons licence and your intended use is not permitted by statutory regulation or exceeds the permitted use, you will need to obtain permission directly from the copyright holder. To view a copy of this licence, visit http://creativecommons.org/licenses/by/4.0/. The Creative Commons Public Domain Dedication waiver (http://creativecommons.org/publicdomain/zero/1.0/) applies to the data made available in this article, unless otherwise stated in a credit line to the data. 


\section{Background}

NCF1 (p47 $7^{\text {phox }}$ ) is a component of the phagocytic NADPH oxidase complex type 2 (NOX2) that upon sensing of pathogenic stimuli releases reactive oxygen species (ROS) into phagosomes and the extracellular compartment. During this process, cytosolic NCF1 gets phosphorylated and interacts with NCF2 and NCF4. This ternary structure gets translocated to the plasma membrane where it associates with the cytochrome complexes CYBB and CYBA to form NOX2. Subsequently, the NOX2 complex transports electrons from NADPH to oxygen, resulting in the release of a variety of ROS. Loss-of-function variants in NCF1 and other genes coding for components of the NOX2 complex are associated with chronic granulomatous disease (CGD), a primary immunodeficiency that is characterized by granulomatous inflammation and recurrent infections due to defects in ROS-dependent destruction of phagocytized microorganisms. The rare missense variant p.Arg90His (rs 201802880, gnomAD MAF $=0.007)$ in NCF1 was reported as a complexdisease susceptibility factor for systemic lupus erythematosus (SLE) and other autoimmune diseases $[1,2]$. In these studies, the p.Arg90His variant was associated with impaired extracellular ROS production and hyperactivation of the interferon (IFN) type 1 signaling but not with a full CGD clinical phenotype. Aside from its role in phagosome-mediated pathogen clearance, ROS also exhibit intra- and intercellular signaling properties and play an important role in the regulation of inflammation and immune responses [3-5]. Interferon (IFN) signaling is the main mediator of antimicrobial mechanisms and recent studies have suggested that neutrophilderived ROS suppress the activity of type I IFN that is produced by plasmacytoid dendritic cells (pDCs) [6]. pDCs are a unique subset of dendritic cells and the main producers of IFN cytokines in patients with SLE [7]. pDCmediated IFN induces IL-15 production by conventional DCs (cDCs) which in turn activates IFN type II signaling in natural killer cells [8].

Here we characterize a female patient, homozygous for p.Arg90His in NCF1, who presented with autoinflammatory and autoimmune features accompanied by a strong upregulation of IFN-regulated genes. Overall, her clinical features were most consistent with a periodic fever syndrome, while her laboratory findings were suggestive of an autoimmune disorder.

\section{Case presentation}

The patient was born at 39 weeks of gestation with a birth weight of $2.7 \mathrm{~kg}$ and normal Apgar score. At age 18 months, she developed episodes of fever (up to $104.0^{\circ} \mathrm{F}$ ), anorexia and lethargy that recurred every $6-8$ weeks lasting for 7-10 days. Two years into the course of her illness, she began experiencing nausea, vomiting and severe headache with each fever episode. During one episode, her cerebrospinal fluid and brain MRI findings were consistent with aseptic meningitis. She showed signs of failure to thrive, iron deficiency anemia, atrophic skin lesions (Fig. 1a).

Autoantibody testing revealed positive ANA (1:640), anti-Ro $(>100 \mathrm{U} / \mathrm{mL})$ and anti-La $(>12 \mathrm{U} / \mathrm{mL})$ antibodies. The remainder of her specific autoantibodies, including anti-dsDNA and rheumatoid factor, were negative. Both during and between fever episodes, the patient had marked elevation of the erythrocyte sedimentation rate (ESR), but normal to only mildly elevated levels of C-reactive protein (CRP). With two of the fever episodes, she developed a mild macrophage activation syndrome (MAS) with raised serum ferritin, neutropenia, and thrombocytopenia. Otherwise, her complete blood count was normal. Abdominal ultrasound identified small lymph nodes in peripancreatic and splenic hilum regions and chest $\mathrm{x}$-ray showed mild bilateral perihilar peribronchovascular linear opacities. The Schirmer test for ocular dryness and Rose Bengal ocular staining did not show any ocular sicca. She had no clinical stigmata of SLE, Sjögren syndrome or other autoimmune disease until the age of seven, when she developed the first of two episodes of parotitis that resolved spontaneously (Table 1). A complete set of investigations for recurrent fever did not reveal any infectious or malignant etiology. Due to the absence of infections and a normal neutrophil oxidative burst capacity, her clinical features were not consistent with typical CGD (Fig. 1b).

Her fever episodes responded well to systemic steroids (Dexamethasone, 0,25-4.5 mg) and recurred upon weaning. A trial of hydroxychloroquine did not alter the frequency or severity of disease flares. Given features of MAS with her febrile episodes, and the responsiveness of MAS in other situations to IL-1 inhibition, she received treatment with anakinra (100 mg $[6 \mathrm{mg} / \mathrm{kg}])$, at the onset of the fever, which reduced the height of the fever peaks to some extent but did not completely abort the episodes. An attempt at daily prophylactic anakinra also did not reduce the frequency of episodes, suggesting that her disease was not primarily mediated by dysregulated interleukin-1 activity. In view of results that showed upregulation of predominantly interferonstimulated genes (ISGs) (see below), our patient was treated with the JAK inhibitor tofacitinib (5-10 mg), which resulted in decreased serum ferritin levels and frequency of fevers (Suppl. Fig. 1C), but only a partial clinical effect was seen. Our patient was subsequently started on sirolimus (rapamycin, $2 \mathrm{mg}$ ), with which we have been able to wean off her corticosteroids while maintaining complete resolution of fevers. Exome sequencing (ES) was performed on the patient and her parents, who are of Indian ancestry. The proband was 
a
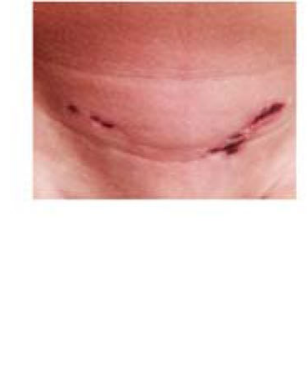

C

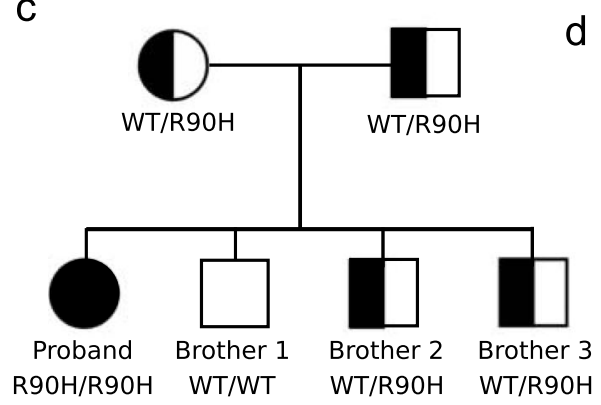

d b

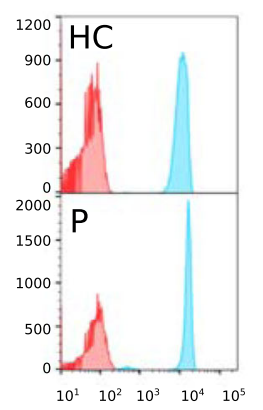

Neutrophil NCF1 expression

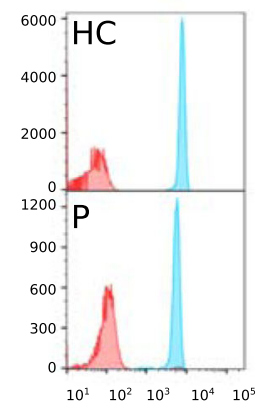

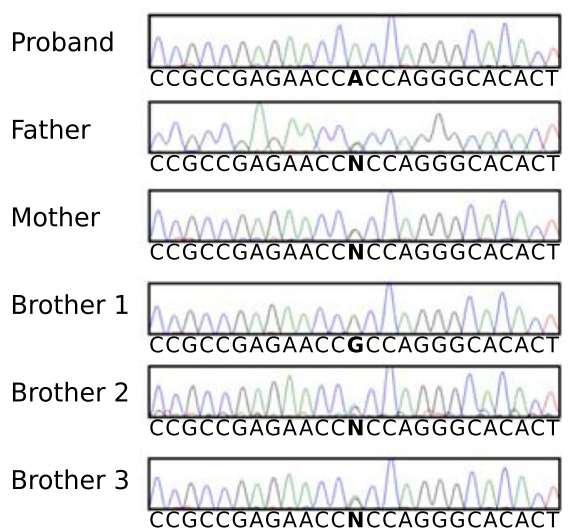

Fig. 1 Patient presentation and NCF1 p.Arg90His genotyping in the proband and her family. a: Atrophic skin lesion on lower abdomen of patient homozygous for NCF1, p.Arg90His. b: Residual oxidase activity of neutrophils and NCF1 expression in patient and healthy control. Left: Residual oxidase activity of neutrophils was determined using dihydrorhodamine (DHR) oxidation by flow cytometry. Right: NCF1 expression in patient and healthy control. NCF1 expression in neutrophils is presented as mean fluorescence intensity. Both panels: Red histograms represent neutrophils treated with buffer under basal conditions; blue histograms represent neutrophils in response to PMA ( $400 \mathrm{ng} / \mathrm{mL}$ ). c: Pedigree of the family with the recessively inherited homozygous pathogenic variant p.Arg90His in the NCF1 gene. d: Sanger sequencing validation in proband and family. Sanger sequencing confirmed the homozygous variant NCF1, c.269G > A, p.Arg90His in the patient. Her parents and two brothers are heterozygous for the same variant

found to be homozygous for the rare missense variant p.Arg90His in the NCF1 gene, while her parents were healthy carriers for this variant (Fig. 1c). Three other healthy siblings were either carriers for the variant or wildtype. No other plausible candidate gene variants were identified under the assumption of either a dominantly or a recessively inherited disease (Suppl. Table 1). Since the presence of two pseudogenes, $N C F 1 B / C$, might interfere with the alignment algorithms, the GTGT sequence at the start of exon 2 of NCF1 was used to discriminate between $N C F 1 B / C$ and NCF1 [1]. This genotype was confirmed by Sanger sequencing in the patient and her family members (Fig. 1d and Suppl. Fig. $1 \mathrm{~A})$. To determine the copy number of $N C F 1 B / C$ and $N C F 1$, a ddPCR assay containing probes specific for either the GTGT in $N C F 1$ or the $\triangle \mathrm{GT}$ sequence in $N C F 1 B / C$ was performed [9]. Since a total of 6 copies of $N C F 1 / N C F 1 B / N C F 1 C$ are expected, healthy controls are predicted to have 2 GTGT copies vs $4 \Delta G$ T copies expressed as $2 / 6$. In p47phox CGD, the most common pathogenic variant is $\triangle \mathrm{GT}$ in NCF1. Individuals who are carriers for this CGD-associated p47phox variant are predicted to have 1 GTGT copy and $5 \Delta$ GT copies, or $1 / 6$. In contrast, p47phox CGD patients are predicted to have 0 GTGT copies and $6 \Delta$ GT copies, or $0 / 6$. The proportional ratio of $\mathrm{GTGT} /(\mathrm{GTGT}+\Delta \mathrm{GT})$ of the patient and the healthy control sample were $2 / 6$ which is equivalent to the expected 2 GTGT copies and $4 \Delta G T$ copies (Suppl. Fig. 1B). A custom designed NanostringRNA expression array of 32 IFN-regulated and other inflammatory genes showed moderate to strong upregulation of predominantly interferon-stimulated genes (ISGs) in peripheral blood of the patient during (Patient-F) and in between flares (Patient-NF) compared to heathy controls. A patient with SLE due to complement C1R deficiency served as a positive control (Fig. 2a) [10]. Quantitative RT-PCR for 10 IFN-induced genes confirmed the Nanostring-RNA analysis. The strongest upregulation during and in between flares was seen for IFI27, CXCL10, USP18, and ISG15 (Fig. 2b). Of note is 
Table 1 Comparison of clinical features of patient with homozygous NCF1, p.Arg90His to pediatric SLE patients

\begin{tabular}{|c|c|c|}
\hline Disease Features & Pediatric SLE Patients $^{a}$ & NCF1 Variant Patient \\
\hline Age of disease onset & Average 12 years & 18 months \\
\hline Fever & $35-100 \%$ & + \\
\hline Pattern & With active disease & Recurrent episodes \\
\hline Cutaneous Involvement & $60-90 \%$ & + \\
\hline Manifestations & $\begin{array}{l}\text { Malar rash; photosensitivity; discoid rash; mucosal } \\
\text { ulceration }\end{array}$ & Inflamed linear lesion with atrophic scar \\
\hline Alopecia & $10-30 \%$ & + \\
\hline Arthritis & $60-90 \%$ & - \\
\hline $\begin{array}{l}\text { Neuropsychiatric } \\
\text { involvement }\end{array}$ & $15-95 \%$ & + \\
\hline Manifestations & $\begin{array}{l}\text { Headaches; cognitive dysfunction; seizures; } \\
\text { psychosis }\end{array}$ & Severe headache with fever \\
\hline Pericarditis & $20-30 \%$ & - \\
\hline Pleuritis & $20-30 \%$ & - \\
\hline Renal Disease & $48-100 \%$ & - \\
\hline Gastrointestinal Disease & $24-40 \%$ & + \\
\hline Manifestations & $\begin{array}{l}\text { Peritonitis (sterile); abnormal liver function; } \\
\text { pancreatitis; colitis }\end{array}$ & Focal minimal triaditis \\
\hline Hematological disorders & $33-75 \%$ & + \\
\hline Manifestations & $\begin{array}{l}\text { Anemia; lymphopenia > neutropenia; } \\
\text { thrombocytopenia }\end{array}$ & $\begin{array}{l}\text { Chronic anemia; intermittent thrombocytopenia, neutropenia and } \\
\text { lymphopenia }\end{array}$ \\
\hline Inflammatory Markers & ESR correlates with active disease; CRP often normal & ESR elevated disproportionate to CRP with fever \\
\hline \multicolumn{3}{|l|}{ Autoantibodies } \\
\hline ANA & $>99 \%$ & + \\
\hline Anti-ds DNA & $84-100 \%$ & - \\
\hline Anti-Sm & $23-48 \%$ & - \\
\hline Anti-Ro & $38-54 \%$ & + \\
\hline Anti-La & $16-32 \%$ & + \\
\hline
\end{tabular}

SLE systemic lupus erythematosus; ESR erythrocyte sedimentation rate; CRP C-reactive protein; ANA antinuclear antibody; ds double-stranded; Sm Smith ${ }^{a}$ Adapted from Cassidy JT, Petty RE, Laxer RM, Lindsley CB. Textbook of Pediatric Rheumatology, 6th edition. 2011. Saunders Elsevier; Philadelphia, PA

that the expression of receptors for type I and type II IFN signaling (IFNAR1, IFNAR2, and IFNGR) was mostly downregulated in the patient, which raises the question whether type III IFN signaling pathway may be contributory to the interferon signature. Additionally, by qRT-PCR we showed that RNA expression of the type I IFN-induced cytokine IL-15 was significantly elevated in the patient ( $p$-value $=0.001$; Fig. $2 \mathrm{c})$. Together these data corroborate that the enhanced inflammatory phenotype in this patient is mediated by an upregulation in interferon signaling pathways.

Whole blood cell cytokine analysis, either unstimulated or stimulated, showed strong differences in the patient's cytokine profile compared to healthy family members and confirmed the observed type I IFN gene expression signature. The most elevated cytokines at baseline were IFN- $\alpha 2$, IL-3, TNF- $\beta$ and $\beta$-NGF. All four cytokines were not further upregulated upon various stimulations (Fig. 2d). Interestingly, elevated serum concentrations of three of the four upregulated cytokines were previously associated with increased disease activity and clinical severity of SLE [11-14].

Flow cytometry immunophenotyping analysis in the patient revealed an increase in intermediate monocytes $\left(\mathrm{CD} 14^{++} \mathrm{CD} 16^{+}\right)$compared to her healthy family members (Fig. 2e). Intermediate monocytes play an important role in disease progression and severity in SLE, rheumatoid arthritis and autoinflammatory diseases [15-17]. Furthermore, a reduction in the patient's pDCs $\left(\mathrm{CD} 123^{+} / \mathrm{CD} 11 \mathrm{c}^{-}\right)$was observed (Fig. 2f). This finding is in agreement with previous reports on reduced numbers of pDCs in peripheral blood in patients with SLE and type I interferonopathies [18]. Early studies suggested that reduced levels of peripheral pDCs were due to their localization in specific tissues and consequently, high numbers of pDCs were identified in the skin and kidneys of patients with autoimmune disease [19]. Subsequently these studies concluded that active pDCs have migrated to the sites of inflammation [20]. Activated pDCs express high levels of C-C-Motiv-Chemokine-Receptor 


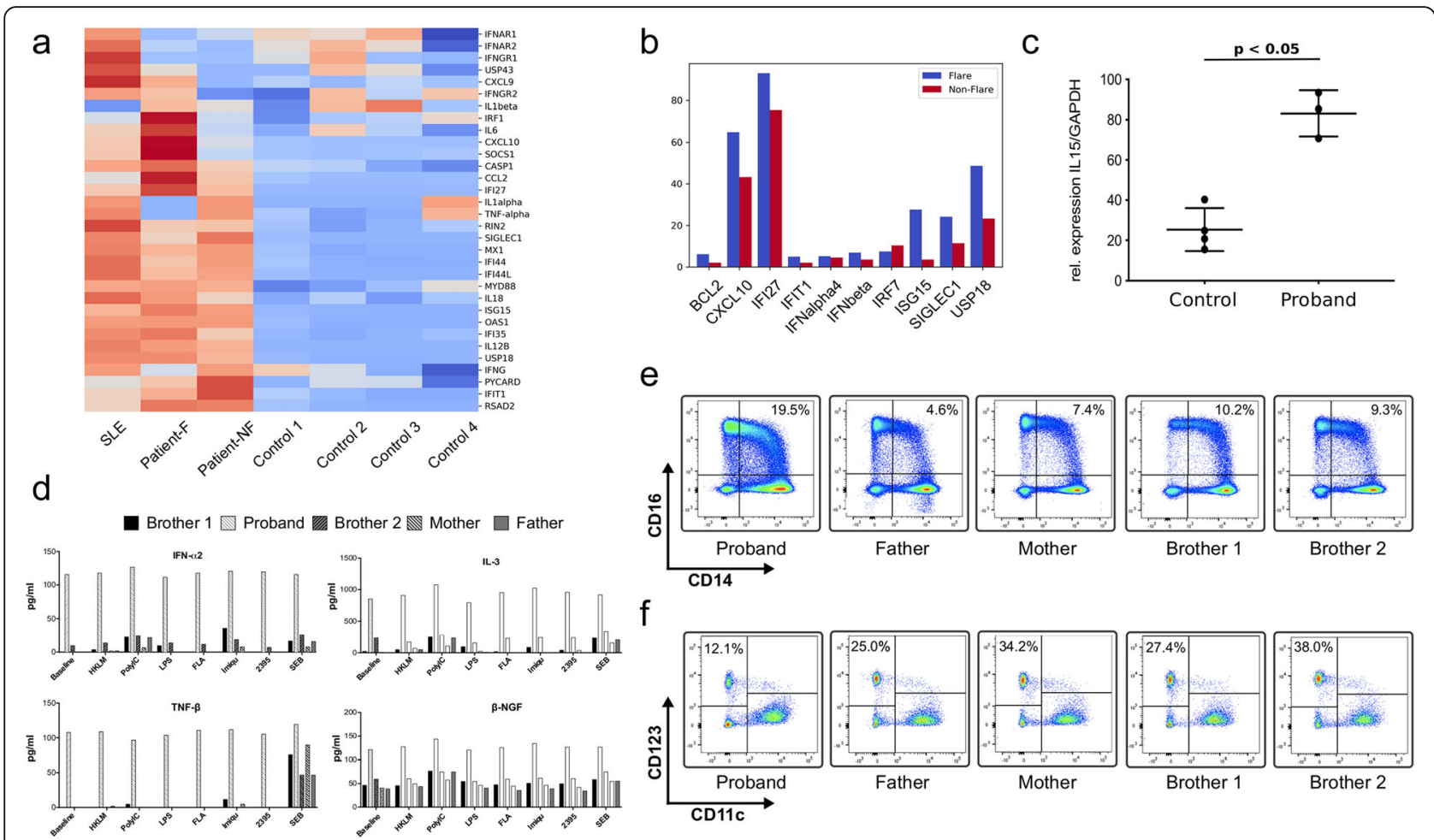

Fig. 2 Interferon signature analysis, inflammatory cytokine profile and immune phenotyping in patient and family. a: Nanostring analysis for IFN signature genes in the patient (Patient- $\mathrm{F}=$ sample taken during flare; Patient-NF, SLE patient with the complement C1R deficiency (SLE) and healthy controls (Control 14). Red, elevated expression compared to control; blue, reduced expression compared to control. b: Quantitative reverse transcription (qRT-PCR) analysis of 10 IFN-related genes shows strong upregulation in the proband compared to control. Shown is fold change to control normalized to GAPDH expression. $\mathbf{c}$ : Quantitative reverse transcription (qRT-PCR) analysis of IL15 in proband and healthy controls. Shown are the relative expression values of IL15/GAPDH. d: IFN-a2, IL-3, TNF- $\beta$ and nerve growth factor $\beta$ (NGF $\beta$ ) cytokine measurement on whole blood cells from the proband, her parents and 2 brothers. Cells were untreated or stimulated with different stimuli (heat-killed Listeria monocytogenes [HKLM] at 107 bacteria/ml, Poly(l:C) at $10 \mu \mathrm{g} / \mathrm{ml}$, lipopolysaccharide [LPS] at $1 \mu \mathrm{g} / \mathrm{ml}$, flagellin [FLA] at $50 \mathrm{ng} / \mathrm{ml}$, imiquimod [Imiqu] at $5 \mu \mathrm{g} / \mathrm{ml}$, ODN2395 [2395] at $5 \mu \mathrm{M}$ and Staphylococcal Enterotoxin B [SEB] at $1 \mu \mathrm{g} / \mathrm{ml})$. e: Quantification of pDCs and intermediate monocytes in the proband, her parents and two brothers. PBMCs were extracted from whole blood and incubated with the monoclonal antibodies anti-CD11c and anti-CD123 for pDC analysis and anti-CD14 and anti-CD16 for the analysis of intermediate monocytes. The data shown here are the only comparisons that achieved nominal statistical significance by the Mann-Whitney $U$ test, which would not withstand correction for multiple comparisons

(CCR) 5 and CCR7 [21] which are responsible for pDCmigration to lymphoid organs and inflamed organs [22]. Interestingly, later studies report normal to increased $\mathrm{pDC}$ numbers in the periphery of SLE patients [23, 24]. These distinct observations are likely due to differences in disease state and progression and it is likely that $\mathrm{pDCs}$ that were recruited to specific target organs display different characteristics than peripheral blood pDCs.

\section{Discussion and conclusions}

In 2017, the rare variant p.Arg90His in NCF1 was associated with susceptibility to autoimmune diseases in various populations and a significantly younger age of diagnosis of SLE (30.3 vs. 35.9 years; $p=2.0 \times$ 10-6) [1, 2]. Individuals who carry the p.Arg90His variant do not present with immunodeficiency, indicating a sustained ability to generate a phagosomal respiratory burst. The phox homology (PX) domain of NCF1 exhibits a strong binding affinity to the plasma membrane component phosphatidylinositol-3, 4-bisphosphate, while NCF4 preferentially binds to phosphatidylinositol-3-phosphate, highly abundant in the phagosomal membrane [25]. The p.Arg90 variant is located in the phosphoinositide-binding pocket of the PX domain of NCF1 and mutagenesis of this residue mainly reduces binding of cytosolic NCF1 to the plasma membrane but has minimal effect on translocation to the phagosomal membrane [26]. Patient cells carrying the p.Arg90His variant exhibit normal intracellular levels of ROS but show reduced extracellular ROS production in neutrophils [2]. In agreement with this, our patient exhibits a normal intracellular neutrophil oxidative burst capacity in response to PMA and has not had any significant infections. Reduced neutrophilic ROS release can 
trigger IFN gene expression by upregulation of IL-15 signaling, and elevated IL-15 levels induce exaggerated autoantibody production through activation of IFN- $\gamma$ in NK cells [27]. In line with this, our patient shows high IL-15 cytokine gene expression levels and upregulation of IFN-regulated genes. Interestingly, CGD patients have increased risk of developing autoimmune disorders and were shown to exhibit increased expression of IFN-regulated genes [28, 29].

Olsson et al. demonstrated an association of p.Arg90His with IFN type I signaling in a cohort of patients with rheumatoid arthritis but not SLE. They speculated that extracellular ROS is important for the initiation of IFN type I signaling, but once initiated, IFN signaling is self-sustaining [2]. Thus, the strong IFN signature in fully developed SLE may outweigh the genetic effect of the p.Arg90His variant.

Our patient exhibits persistently high titer autoantibodies, including ANA, anti-Ro and anti-La, which are commonly seen in SLE or primary Sjögren syndrome. Despite the biological markers, she showed no clinical features of either disease until the age of seven, when she developed her first episode of recurrent parotitis. This is in agreement with the observation that onset of clinical SLE is preceded by the development of a variety of autoantibodies many years before the first clinical signs of disease [30]. Similarly, as seen in patients with SLE and not in patients with autoinflammatory diseases associated with inflammasome activation, our patient had a consistently normal or only minimally elevated CRP and a poor response to IL-1 blockade.

The finding of an ISG signature in our patient suggested that blocking interferon signaling may be an effective treatment for her disease. Type I interferon receptors signal via Janus kinase (JAK) 1 and Tyrosine Kinase 2 (TYK2), while Type II interferon receptor ligation results in JAK1 and JAK2 activation [31]. Our patient was treated with the JAK inhibitor tofacitinib and while this confirmed a partial effect, we speculate that the lack of full response may relate to the specificity of kinase inhibition by tofacitinib, as it has been shown to act on JAK3 more effectively than JAK1, JAK2 or TYK2 [32]. As we were unable to obtain an alternate JAK inhibitor for the patient, she was started on a trial of sirolimus (rapamycin), with which we have been able to wean off her corticosteroids while maintaining complete resolution of fevers. Of note, sirolimus has previously been shown to act on pDCs by suppressing their production of type I interferons [33].

Due to the presence of two highly homologous, nonfunctional NCF1 pseudogenes, the p.Arg90His variant was not previously identified in GWAS as a susceptibility allele for SLE and correct genotyping of the NCF1 gene requires highly specific methods, including exact copy number determination and NCF1-specific PCR techniques. It is also important to note that allele frequency databases such as the Genome Aggregation Database (gnomAD) and the $1000 \mathrm{Ge}-$ nomes Project use short sequence reads and might therefore fail to correctly identify the p.Arg90His and other variants in this gene.

The allele frequency of p.Arg90His variant differs in various populations, with highest numbers in East Asians. This variant is far less common in European and South Asian, including Indian, populations [1, 34]. Because SLE is a polygenic disease, we considered a possibility that the early-onset severe symptoms in our patient might be explained by the presence of additional susceptibility alleles that cumulatively contribute to disease manifestations. Such synergistic interactions between susceptibility alleles are a well-characterized disease mechanism in SLE and many other autoimmune diseases [35, 36]. Risk loci not only can affect age of onset, but also are strongly associated with a severity of clinical manifestations including immunological and hematologic disorder, renal disease, and mucocutaneous ulceration [36]. We therefore determined the presence of common and rare SLE-associated variants in exome data from this family and did indeed find an enrichment of other risk alleles in our patient (Suppl. Table 2). Compared to the other 3 siblings, the patient inherited more risk variants either in a heterozygous or homozygous state. The distribution of these variants was most similar with Brother 1, yet the patient carries additional risk alleles at two gene loci (DNASE1 and TYK2). The additive effect of these SLE-associated variants may further contribute to the severity and earlier onset of disease in our patient.

In summary, the p.Arg90His variant was reported previously as a susceptibility allele in adults with a fully developed autoimmune phenotype. The present work provides evidence that homozygosity of this variant can be associated with childhood-onset immune dysregulation that includes features of systemic inflammation, including dysregulated interferon activity, and persistently elevated autoantibodies. This finding is of particular interest since our patient may be evolving toward a fully developed autoimmune phenotype later in life. Furthermore, these findings suggest that patients with unexplained recurrent fever and autoantibodies may have a genetic disorder in the interferon signaling pathway that should be investigated by interferon gene signature testing and / or genetic testing. Such discoveries might help in the diagnosis of other patients with atypical manifestations of SLE and autoinflammatory disease and also guide new targeted therapies. 


\section{Abbreviations}

CDCs: Conventional DCs; CGD: Chronic granulomatous disease; CRP: Creactive protein; ESR: Erythrocyte sedimentation rate; IG: Immunoglobulin; ISG: Interferon-stimulated genes; JAK: Janus kinase; MAS: Macrophage activation syndrome; NOX2: NADPH oxidase complex type 2; PX: Phox homology; PDCs: Plasmacytoid dendritic cells; ROS: Reactive oxygen species; SLE: Systemic lupus erythematosus; TYK: Tyrosine Kinase

\section{Supplementary Information}

The online version contains supplementary material available at https://doi. org/10.1186/s12969-021-00536-y.

\section{Additional file 1.}

\section{Acknowledgements}

We thank the patient, her family, and the healthy controls, for their enthusiastic support during this study.

\section{Authors' contributions}

OS, LH, WLT, DBK performed the major part of the experimental work. $L H$, $D L S, M G, R M L, D D$ were involved in acquisition of data. $O S, L H, I A, D L K, R M L$, DD wrote the manuscript. All authors revised and approved the final manuscript.

\section{Funding}

This research was supported by the Intramural Research Programs of the NHGRI, NIAMS, NIAID, the NIH Clinical Center, and the German Research Foundation. Open Access funding provided by the National Institutes of Health $(\mathrm{NIH})$

\section{Availability of data and materials}

All data generated or analyzed during this study are included in this published article. Exome sequencing raw data is available upon request.

\section{Declarations}

\section{Ethics approval and consent to participate}

The patient and her healthy family members provided signed informed consent to participate in the study. The study was approved by the NIDDK NIAMS Institutional Review Board (14-AR-0200).

\section{Consent for publication}

The patient and her healthy family members provided signed informed consent to participate to publish the material.

\section{Competing interests}

The authors declare that the research was conducted in the absence of any commercial or financial relationships that could be construed as a potential conflict of interest.

\section{Author details}

${ }^{1}$ National Human Genome Research Institute, National Institutes of Health, Bethesda, USA. ${ }^{2}$ The Hospital for Sick Children, University of Toronto, Toronto, Canada. ${ }^{3}$ National Institute of Arthritis and Musculoskeletal and Skin Diseases, National Institutes of Health, Bethesda, USA. ${ }^{4}$ National Institute of Allergy and Infectious Diseases, National Institutes of Health, Bethesda, USA.

${ }^{5}$ Frederick National Laboratory for Cancer Research, Frederick, USA.

Received: 23 November 2020 Accepted: 11 March 2021

Published online: 23 April 2021

\section{References}

1. Zhao J, Ma J, Deng Y, Kelly JA, Kim K, Bang SY, Lee HS, Li QZ, Wakeland EK, Qiu R, Liu M, Guo J, Li Z, Tan W, Rasmussen A, Lessard CJ, Sivils KL, Hahn BH, Grossman JM, Kamen DL, Gilkeson GS, Bae SC, Gaffney PM, Shen N, Tsao BP. A missense variant in NCF1 is associated with susceptibility to multiple autoimmune diseases. Nat Genet. 2017:49(3):433-7. https://doi. org/10.1038/ng.3782
2. Olsson LM, Johansson AC, Gullstrand B, Jonsen A, Saevarsdottir S, Ronnblom $L$, et al. A single nucleotide polymorphism in the NCF1 gene leading to reduced oxidative burst is associated with systemic lupus erythematosus. Ann Rheum Dis. 2017;76(9):1607-13. https://doi.org/10.1136/annrheumdis-2 017-211287.

3. Zhang Y, Choksi S, Chen K, Pobezinskaya Y, Linnoila I, Liu Z-G. ROS play a critical role in the differentiation of alternatively activated macrophages and the occurrence of tumor-associated macrophages. Cell Res. 2013;23(7):898914. https://doi.org/10.1038/cr.2013.75.

4. Mittal M, Siddiqui MR, Tran K, Reddy SP, Malik AB. Reactive oxygen species in inflammation and tissue injury. Antioxid Redox Signal. 2014;20(7):1126-67. https://doi.org/10.1089/ars.2012.5149.

5. D'Autreaux B, Toledano MB. ROS as signalling molecules: mechanisms that generate specificity in ROS homeostasis. Nat Rev Mol Cell Biol. 2007;8(10): 813-24. https://doi.org/10.1038/nrm2256.

6. Huang X, Li J, Dorta-Estremera S, Di Domizio J, Anthony SM, Watowich SS, et al. Neutrophils regulate Humoral autoimmunity by restricting interferongamma production via the generation of reactive oxygen species. Cell Rep. 2015;12(7):1120-32. https://doi.org/10.1016/j.celrep.2015.07.021.

7. Menon M, Blair PA, Isenberg DA, Mauri C. A regulatory feedback between Plasmacytoid dendritic cells and regulatory B cells is aberrant in systemic lupus Erythematosus. Immunity. 2016;44(3):683-97. https://doi.org/10.1016/j. immuni.2016.02.012

8. Puttur F, Francozo M, Solmaz G, Bueno C, Lindenberg M, Gohmert M, Swallow M, Tufa D, Jacobs R, Lienenklaus S, Kühl AA, Borkner L, Cicin-Sain L, Holzmann B, Wagner H, Berod L, Sparwasser T. Conventional dendritic cells confer protection against mouse Cytomegalovirus infection via TLR9 and MyD88 signaling. Cell Rep. 2016;17(4):1113-27. https://doi.org/10.1016/j. celrep.2016.09.055

9. Kuhns DB, Hsu AP, Sun D, Lau K, Fink D, Griffith P, Huang DW, Priel DAL, Mendez L, Kreuzburg S, Zerbe CS, de Ravin SS, Malech HL, Holland SM, Wu X, Gallin JI. NCF1 (p47(phox))-deficient chronic granulomatous disease: comprehensive genetic and flow cytometric analysis. Blood advances. 2019; 3(2):136-47. https://doi.org/10.1182/bloodadvances.2018023184.

10. Demirkaya E, Zhou Q, Smith CK, Ombrello MJ, Deuitch N, Tsai WL, Hoffmann P, Remmers EF, Takeuchi M, Park YH, Chae JJ, Barut K, Simsek D, Adrovic A, Sahin S, Caliskan S, Chandrasekharappa SC, Hasni SA, Ombrello AK, Gadina M, Kastner DL, Kaplan MJ, Kasapcopur O, Aksentijevich I. Brief report: deficiency of complement 1 r subcomponent in early-onset systemic lupus Erythematosus: the role of disease-modifying alleles in a monogenic disease. Arthritis Rheumatology. 2017;69(9):1832-9. https://doi.org/10.1002/art.40158.

11. Aalto K, Korhonen $L$, Lahdenne P, Pelkonen P, Lindholm D. Nerve growth factor in serum of children with systemic lupus erythematosus is correlated with disease activity. Cytokine. 2002;20(3):136-9. https://doi.org/10.1006/ cyto.2002.1991.

12. Fishman P, Kamashta M, Ehrenfeld M, Vianna J, Hughes GR, Sredni D, et al Interleukin-3 immunoassay in systemic lupus erythematosus patients: preliminary data. Int Arch Allergy Immunol. 1993;100(3):215-8. https://doi. org/10.1159/000236414.

13. Renner K, Hermann FJ, Schmidbauer K, Talke Y, Gomez MR, Schiechl G, Schlossmann J, Brühl H, Anders HJ, Mack M. IL-3 contributes to development of lupus nephritis in MRL/lpr mice. Kidney Int. 2015;88(5): 1088-98. https://doi.org/10.1038/ki.2015.196.

14. Niewold TB, Clark DN, Salloum R, Poole BD. Interferon alpha in systemic lupus erythematosus. J Biomed Biotechnol. 2010;2010:948364.

15. Tsukamoto M, Seta N, Yoshimoto K, Suzuki K, Yamaoka K, Takeuchi T. CD14 bright CD16+ intermediate monocytes are induced by interleukin-10 and positively correlate with disease activity in rheumatoid arthritis. Arthritis Research \& Therapy. 2017;19(1):28. https://doi.org/10.1186/s13075-016-1216-6.

16. Zhu H, Hu F, Sun X, Zhang X, Zhu L, Liu X, et al. CD16(+) Monocyte Subset Was Enriched and Functionally Exacerbated in Driving T-Cell Activation and B-Cell Response in Systemic Lupus Erythematosus. Frontiers Immunol. 2016; 7:512.

17. Grip O, Bredberg A, Lindgren S, Henriksson G. Increased subpopulations of CD16(+) and CD56(+) blood monocytes in patients with active Crohn's disease. Inflamm Bowel Dis. 2007;13(5):566-72. https://doi.org/10.1002/ibd.20025.

18. Rodero MP, Decalf J, Bondet V, Hunt D, Rice Gl, Werneke S, McGlasson SL, Alyanakian MA, Bader-Meunier B, Barnerias C, Bellon N, Belot A, Bodemer C, Briggs TA, Desguerre I, Frémond ML, Hully M, van den Maagdenberg AMJM, Melki I, Meyts I, Musset L, Pelzer N, Quartier P, Terwindt GM, Wardlaw J, Wiseman S, Rieux-Laucat F, Rose Y, Neven B, Hertel C, Hayday A, Albert ML, 
Rozenberg F, Crow YJ, Duffy D. Detection of interferon alpha protein reveals differential levels and cellular sources in disease. J Exp Med. 2017;214(5): 1547-55. https://doi.org/10.1084/jem.20161451.

19. Vermi W, Lonardi S, Morassi M, Rossini C, Tardanico R, Venturini M, Sala R, Tincani A, Poliani PL, Calzavara-Pinton PG, Cerroni L, Santoro A, Facchetti F. Cutaneous distribution of plasmacytoid dendritic cells in lupus erythematosus. Selective tropism at the site of epithelial apoptotic damage. Immunobiology. 2009;214(9-10):877-86. https://doi.org/10.1016/j.imbio.2 009.06.013.

20. Fiore N, Castellano G, Blasi A, Capobianco C, Loverre A, Montinaro V, Netti S, Torres D, Manno C, Grandaliano G, Ranieri E, Schena FP, Gesualdo L. Immature myeloid and plasmacytoid dendritic cells infiltrate renal tubulointerstitium in patients with lupus nephritis. Mol Immunol. 2008:45(1): 259-65. https://doi.org/10.1016/j.molimm.2007.04.029.

21. Seth S, Oberdörfer L, Hyde R, Hoff K, Thies V, Worbs T, Schmitz S, Förster R. CCR7 essentially contributes to the homing of plasmacytoid dendritic cells to lymph nodes under steady-state as well as inflammatory conditions. J Immunol. 2011;186(6):3364-72. https://doi.org/10.4049/jimmunol.1002598.

22. Umemoto $\mathrm{E}$, Otani $\mathrm{K}$, Ikeno $T$, Verjan Garcia N, Hayasaka H, Bai Z, Jang MH, Tanaka T, Nagasawa T, Ueda K, Miyasaka M. Constitutive plasmacytoid dendritic cell migration to the splenic white pulp is cooperatively regulated by CCR7- and CXCR4-mediated signaling. J Immunol. 2012;189(1):191-9. https://doi.org/10.4049/jimmunol.1200802.

23. Chan VS-F, Nie Y-J, Shen N, Yan S, Mok M-Y, Lau C-S. Distinct roles of myeloid and plasmacytoid dendritic cells in systemic lupus erythematosus. Autoimmun Rev. 2012;11(12):890-7. https://doi.org/10.1016/j.autrev.2012.03.004.

24. Jin O, Kavikondala S, Sun L, Fu R, Mok MY, Chan A, Yeung J, Lau CS. Systemic lupus erythematosus patients have increased number of circulating plasmacytoid dendritic cells, but decreased myeloid dendritic cells with deficient CD83 expression. Lupus. 2008;17(7):654-62. https://doi. org/10.1177/0961203308089410.

25. Karathanassis D, Stahelin RV, Bravo J, Perisic O, Pacold CM, Cho W, Williams RL. Binding of the PX domain of p47(phox) to phosphatidylinositol 3,4bisphosphate and phosphatidic acid is masked by an intramolecular interaction. EMBO J. 2002;21(19):5057-68. https://doi.org/10.1093/emboj/ cdf519.

26. Ueyama T, Tatsuno T, Kawasaki T, Tsujibe S, Shirai Y, Sumimoto H, Leto TL, Saito N. A regulated adaptor function of p40phox: distinct p67phox membrane targeting by p40phox and by p47phox. Mol Biol Cell. 2007;18(2): 441-54. https://doi.org/10.1091/mbc.e06-08-0731.

27. Huntington ND. The unconventional expression of $\mathrm{IL}-15$ and its role in NK cell homeostasis. Immunol Cell Biol. 2014;92(3):210-3. https://doi.org/10.103 8/icb.2014.1.

28. De Ravin SS, Naumann N, Cowen EW, Friend J, Hilligoss D, Marquesen M, et al. Chronic granulomatous disease as a risk factor for autoimmune disease. J Allergy Clin Immunol. 2008;122(6):1097-103. https://doi.org/10.101 6/j.jaci.2008.07.050

29. Kelkka T, Kienhofer D, Hoffmann M, Linja M, Wing K, Sareila O, et al. Reactive oxygen species deficiency induces autoimmunity with type 1 interferon signature. Antioxid Redox Signal. 2014;21(16):2231-45. https://doi.org/10.1 089/ars.2013.5828.

30. Arbuckle MR, McClain MT, Rubertone MV, Scofield RH, Dennis GJ, James JA, et al. Development of autoantibodies before the clinical onset of systemic lupus erythematosus. N Engl J Med. 2003;349(16):1526-33. https://doi.org/1 0.1056/NEJMoa021933.

31. Furumoto $Y$, Gadina $M$. The arrival of JAK inhibitors: advancing the treatment of immune and hematologic disorders. BioDrugs. 2013;27(5):4318. https://doi.org/10.1007/s40259-013-0040-7.

32. Changelian PS, Flanagan ME, Ball DJ, Kent CR, Magnuson KS, Martin WH, et al. Prevention of organ allograft rejection by a specific Janus kinase 3 inhibitor. Science (New York, NY). 2003;302(5646):875-8.

33. Boor PP, Metselaar HJ, Mancham S, van der Laan $\sqcup$, Kwekkeboom J. Rapamycin has suppressive and stimulatory effects on human plasmacytoid dendritic cell functions. Clin Exp Immunol. 2013;174(3):389-401. https://doi. org/10.1111/cei.12191.

34. Yokoyama N, Kawasaki A, Matsushita T, Furukawa H, Kondo Y, Hirano F, Sada KE, Matsumoto I, Kusaoi M, Amano H, Nagaoka S, Setoguchi K, Nagai T, Shimada K, Sugii S, Hashimoto A, Matsui T, Okamoto A, Chiba N, Suematsu E, Ohno S, Katayama M, Migita K, Kono H, Hasegawa M, Kobayashi S, Yamada H, Nagasaka K, Sugihara T, Yamagata K, Ozaki S, Tamura N, Takasaki Y, Hashimoto H, Makino H, Arimura Y, Harigai M, Sato S,
Sumida T, Tohma S, Takehara K, Tsuchiya N. Association of NCF1 polymorphism with systemic lupus erythematosus and systemic sclerosis but not with ANCA-associated vasculitis in a Japanese population. Sci Rep. 2019;9(1):16366. https://doi.org/10.1038/s41598-019-52920-0.

35. Tanhapour M, Miri A, Vaisi-Raygani A, Bahrehmand F, Kiani A, Rahimi Z, Pourmotabbed T, Shakiba E. Synergism between apolipoprotein $E \mathcal{E} 4$ allele and paraoxonase (PON1) 55-M allele is associated with risk of systemic lupus erythematosus. Clin Rheumatol. 2018;37(4):971-7. https://doi.org/10.1 007/s10067-017-3859-3.

36. Taylor KE, Chung SA, Graham RR, Ortmann WA, Lee AT, Langefeld CD, Jacob CO, Kamboh MI, Alarcón-Riquelme ME, Tsao BP, Moser KL, Gaffney PM, Harley JB, Petri M, Manzi S, Gregersen PK, Behrens TW, Criswell LA. Risk alleles for systemic lupus Erythematosus in a large case-control collection and associations with clinical subphenotypes. PLoS Genet. 2011;7(2): e1001311. https://doi.org/10.1371/journal.pgen.1001311.

\section{Publisher's Note}

Springer Nature remains neutral with regard to jurisdictional claims in published maps and institutional affiliations.

\section{Ready to submit your research? Choose BMC and benefit from:}

- fast, convenient online submission

- thorough peer review by experienced researchers in your field

- rapid publication on acceptance

- support for research data, including large and complex data types

- gold Open Access which fosters wider collaboration and increased citations

- maximum visibility for your research: over $100 \mathrm{M}$ website views per year

At BMC, research is always in progress.

Learn more biomedcentral.com/submissions 